\title{
Pushing the limits of molecular crystal structure determination from powder diffraction data in high-throughput chemical environments
}

Article

Accepted Version

Creative Commons: Attribution-Noncommercial-No Derivative Works 4.0

Kabova, E. A., Blundell, C. D. and Shankland, K. (2018) Pushing the limits of molecular crystal structure determination from powder diffraction data in high-throughput chemical environments. Journal of Pharmaceutical Sciences, 107 (8). pp. 2042-2047. ISSN 0022-3549 doi:

https://doi.org/10.1016/j.xphs.2018.04.010 Available at https://centaur.reading.ac.uk/76609/

It is advisable to refer to the publisher's version if you intend to cite from the work. See Guidance on citing.

To link to this article DOI: http://dx.doi.org/10.1016/j.xphs.2018.04.010

Publisher: Elsevier

All outputs in CentAUR are protected by Intellectual Property Rights law, including copyright law. Copyright and IPR is retained by the creators or other copyright holders. Terms and conditions for use of this material are defined in the End User Agreement. 


\section{www.reading.ac.uk/centaur}

\section{CentAUR}

Central Archive at the University of Reading

Reading's research outputs online 


\title{
Pushing the limits of molecular crystal structure determination from powder diffraction data in high-throughput chemical environments
}

\author{
Elena A. Kabova ${ }^{1, *}$, Charles D. Blundell ${ }^{2}$ and Kenneth Shankland ${ }^{1}$ \\ ${ }^{1}$ School of Pharmacy, University of Reading, Whiteknights, P.O. Box 224, Reading, RG6 6AD, \\ United Kingdom \\ ${ }^{2}$ C4X Discovery, Manchester One, 53 Portland Street, Manchester, M1 3LD, United Kingdom \\ * Correspondence to: Elena Kabova (Telephone: +44 118378 7425). E-mail address: \\ e.kabova@reading.ac.uk.
}

\begin{abstract}
Crystal structure determination from powder diffraction data (SDPD) using the DASH software package is evaluated for data recorded using transmission capillary, transmission flat plate and reflection flat plate geometries on a selection of pharmaceutical compounds. We show that transmission capillary geometry remains the best option when crystal structure determination is the primary consideration and, as expected, reflection flat plate geometry is not recommended for SDPD due to preferred orientation effects. However, the quality of crystal structures obtained from transmission plate instruments can be excellent and the convenience factor for sample preparation, throughput and retrieval is higher than that of transmission capillary instruments. Indeed, it is possible to solve crystal structures within an hour of a polycrystalline sample arriving in the laboratory, which has clear implications for making small molecule crystal structures more routinely available to the practising laboratory medicinal chemist. With appropriate modifications to crystal structure determination software, it can be imagined that SDPD could become a rapid turn-around walk-up analytical service in high-throughput chemical environments.
\end{abstract}

Keywords crystallography; crystal structure; X-ray powder diffractometry;

Introduction Small-molecule crystal structures are known to contribute enormously to drug development for both physicochemical and intellectual property reasons. Despite this, they may not be being used as much as they should be by the practicing medicinal chemist in the early stages of drug discovery (Groom \& Cole, 2017). For example, ligand molecule conformations from smallmolecule crystal structures provide very useful comparators with target-bound conformations, which can be used to optimise binding affinity. Additionally, understanding of intermolecular interactions in the crystal lattice can be used to suggest ways to break those interactions and improve the solubility of hits and leads. For at least these reasons, routine access to small-molecule crystal structures is therefore highly desirable. Currently, single-crystal X-ray diffraction remains the gold standard technique for crystal structure determination, but finding suitable conditions to grow a large enough crystal can prove too time-consuming and, all too often, only microcrystals can be grown. In this context, powder X-ray diffraction (PXRD) provides a valuable alternative for determining crystal structures. 
Since the late 1990s, developments in crystal structure determination from powder diffraction data (SDPD) methods have meant that it is often relatively straightforward to solve complex molecular crystal structures from laboratory-based PXRD data alone (Kabova et al., 2017; Shankland et al., 2013; Fernandes et al., 2007; Bushmarinov et al., 2012; Chernyshev et al., 2010; Chernyshev et al., 2009) without the need for the high instrumental resolution that a synchrotron source allows. In principle, therefore, SDPD could be much more routinely accessible to the laboratory chemist. The vast majority of SDPD work on molecular compounds in the laboratory is performed in transmission geometry, with the sample contained in a narrow diameter (typically $0.7 \mathrm{~mm}$ ) glass capillary which is rotated during data collection ("transmission capillary" geometry) to reduce the impact of any preferred orientation in the sample crystallites. Packing the capillary can require considerable time and effort. In the laboratory environment (both academic and industrial) this type of instrumental setup is currently considered somewhat "specialist" and it is not as widely available, nor as widely used, as the conventional Bragg-Brentano reflection ("reflection flat plate" geometry). The latter is much better suited to the routine task of sample identification, which is the primary use of PXRD in academic and industrial labs, because it involves minimal sample preparation and is well suited to automated sample changing. However, it is not particularly well suited to SDPD, because the effects of sample transparency and preferred orientation (PO), which are a consequence of sample presentation, are not conducive to measuring accurate reflection positions and intensities. Whilst sample transparency effects can be largely avoided using zero-background sample holders, preferred orientation remains a significant confounding factor for intensities, and one that is best avoided at the data collection stage.

Intermediate between these two laboratory experimental setups is transmission geometry with a 96 well plate with kapton foil support ("transmission flat plate" geometry), which allows for easy sample preparation, retrieval and automated sample changing, but provides the benefits of using X-rays in transmission. A previous study has compared two transmission diffractometers in the context of indexing of physical forms, but did not explicitly address structure determination using these setups (Florence et al., 2003). Given the advances in software and computing power that have occurred since that publication, and the emphasis of high throughput in the modern laboratory (including the desirable aim of not having to recrystallise samples generated by reactions), it is timely to revisit this type of instrumentation in the context of crystal structure determination. Were it to be possible to routinely solve moderately complex crystal structures using "transmission flat plate" geometry, it could bridge the gap between capillary and flat-plate setups and make small molecule crystal structures more routinely available to the practising laboratory medicinal chemist. To that end, we have examined the performance of the DASH software program (David et al., 2006), which implements a global optimisation approach to SDPD, in solving crystal structures of varying complexity from PXRD data collected using three different instruments, one representing each kind of setup.

Experimental Details of the three powder X-ray diffractometers used in this work are given in Table 1 , whilst the materials used (all sourced from SigmaAldrich) are summarised in Table 2. All samples 
were lightly ground using a mortar and pestle before use. Capillaries of $0.7 \mathrm{~mm}$ internal diameter were loaded to a length of approximately $2 \mathrm{~cm}$ by gently tapping the powder down, using a hollow plastic tube to support the capillary. In the cases of salbutamol, sertraline hydrochloride and carvedilol, 0.5 $\mathrm{mm}$ capillaries were used, due to the limited amounts of these materials available. The transmission flat plate wells were filled with just sufficient material to cover the bottom of a well. The zero background reflection flat plate was smeared with a very thin layer of vacuum grease to provide an adhesive surface, the powder was lightly dusted on that surface and then evenly distributed by tapping. Data collection parameters are given in Table 3. PXRD data obtained were indexed, Pawley fitted (Pawley, 1981) and the crystal structures solved using DASH version 3.3.6. Starting models for SDPD were generated from crystal structures stored on the Cambridge Structural Database (CSD) Version 5.38 (Groom et al., 2016), and the relevant CSD "refcodes" are shown in Table 2. The number of simulated annealing (SA) DASH runs, the number of SA moves utilised in each run and the SA control parameters were based on recommendations made by Kabova (Kabova et al., 2017). For data collected using the reflection flat plate instrument, a March-Dollase correction for preferred orientation was included in DASH as optimisable parameter. Structures were visualised using Mercury CSD version 3.9 (Macrae et al., 2008). The "Crystal Packing Similarity" feature of Mercury was used to confirm agreement between structures considered being solved by $D A S H$ and the reference single-crystal structures. All computer programs were run on a dual 12 core Xeon-based PC running MS Windows 7.

Results For each data set collected, a Pawley fit to the data was performed across the maximum available range, consistent with achieving a stable Pawley fit and attempting to keep the fitted data ranges equal between instruments (Table 4). Table 5 shows the full width at half maximum (FWHM) for selected peaks of carvedilol, whilst Figure 1 shows an overlay of the three data sets collected from the same material.

Success rates (defined as the \% of SA runs that return a crystal structure in good agreement with the reference single-crystal structure) and accuracy in solving the various crystal structures are shown in Tables 6, 7 and 8 .

\section{Discussion}

Perhaps surprisingly to some, the transmission flat plate setup is well capable of providing data of sufficient quality for solving crystal structures of complexities typical of many pharmaceutical compounds. While the resolution and accuracy achievable from the transmission capillary setup is superior, for the practising medicinal chemist interested in questions of molecular conformation, hydrogen-bonding interactions and relative stereochemistry, the structures produced using the transmission flat plate set up are quite sufficient for purpose, as the overlays in Figure 2 and Figure 3 show. It is worth remembering that the solved structures are exactly as output by the simulated annealing (i.e. no subsequent Rietveld refinement) yet are very accurate. 
It is also clear that for the materials studied, only the transmission capillary and transmission flat plate setups are capable of collecting data suitable for reliable crystal structure determination. Whilst some structures can be solved from the reflection flat plate setup, it is no surprise that the effect of preferred orientation of crystallites manifests itself in the data; a cursory glance at the triplet of peaks between $16^{\circ}$ and $18^{\circ} 2 \theta$ in Figure 1 illustrates clearly the distortion of reflection intensities that makes SDPD attempts problematic. The inclusion of a preferred orientation correction in the structure determination process can help mitigate this distortion, but represents an additional complication that is best avoided. The use of a sample holder to allow more sample to be exposed to the beam would certainly improve counting statistics over those obtained with the zero-background plate used in this work, but would do nothing to improve the situation with respect to preferred orientation.

For the structures studied in this work, which are of moderate molecular and crystallographic complexity (Shankland et al., 2013), both transmission capillary and transmission flat plate setups are clearly very good options. Whilst the full width at half maximum values are higher for the transmission flat plate setup than for the transmission capillary, provided the PXRD pattern can be indexed, this is not a significant impediment to global-optimisation based SDPD, as implemented in DASH. The transmission flat plate setup used in this work benefits from the high incident flux afforded by the Göbel mirror associated with the $\mathrm{Cu} X$-ray source, and the presence of $\mathrm{K}_{2}$ radiation is not a significant factor over the data ranges fitted.

Table 6 illustrates that even with the relatively short data collection times used, structures are solved with a high level of success and accuracy. As expected, as molecular and crystallographic complexity rises, success rates drop off (Kabova et al., 2017). Nevertheless, in all cases, high-quality crystal structures were obtained that showed excellent agreement with the reference single crystal structures, as evidenced by the low RMSD values for the 15 molecule overlays performed using Mercury (Table 7 and Figure 3). In the case of the most complex sample, furosemide (22 DoF), the high RMSD of the best structures obtained from the transmission capillary and transmission flat plate setups were a consequence of just one of the furan rings being rotated ca. $90^{\circ}$ with respect to the reference structure. This rotation was easily corrected during subsequent Rietveld refinement, which revealed the presence of a mild degree of preferred orientation in the $\left(\begin{array}{lll}0 & 1 & 0\end{array}\right)$ direction even in the transmission capillary data. Re-running $D A S H$ with a PO correction included as an optimisable parameter returned a solution with the furan correctly oriented, reducing the RMSD relative to the single crystal structure to only $0.132 \AA$.

It is worth noting that relatively short collections were used in this work in order to reflect the requirements of a high-throughput / industrial laboratory environment. For normal lab-based SDPD and subsequent Rietveld refinement for publication, a typical run on a transmission capillary setup would last at least $8 \mathrm{hrs}$ over the range $3-70^{\circ} 2 \theta$, with a variable count time scheme (Shankland et al., 1997) employed. Viewed in this light, the 1 hour data collections used here are very short and sufficient for SDPD and, whilst not for publication-quality Rietveld refinement, the high accuracy of the crystal structures obtained is clear to see. Of course, should publication-quality structures be 
desirable, we would always recommend the use of transmission capillary geometry, either in the lab or at a synchrotron X-ray source.

In order to assess if some structures could still be solved when employing even shorter data collection times, 3 minute scans of mefenamic acid, salbutamol, sertraline hydrochloride and cefadroxil monohydrate, in the range $4^{\circ}-45^{\circ} 2 \theta$, were performed on the transmission flat plate instrument. Structures solutions were attempted using 50 SA runs each comprising $5 \times 10^{6}$ SA moves, giving success rates of $100 \%, 98 \%, 96 \%$ and $10 \%$ respectively. These results serve to highlight the potential of transmission flat plate instruments, coupled with global-optimisation based SDPD in a highthroughput, laboratory environment. The presence of the Göbel mirror in our transmission flat plate setup undoubtedly helps in obtaining good counting statistics in spite of the extremely short data collection time used.

The $D A S H$ structure determination runs do not take long to execute. By way of example, a single SA run consisting of $5 \times 10^{6} \mathrm{SA}$ moves for cefadroxil monohydrate takes only 2 minutes to complete, running on a single core of a $2.3 \mathrm{GHz}$ Xeon E5-2670v3. Multiple CPU cores can be used to perform SA runs in parallel using the MDASH utility (Griffin et al., 2009), giving a near linear speedup as a function of the available cores e.g. $24 \mathrm{SA}$ runs of $5 \times 10^{6} \mathrm{SA}$ moves, running on dual 12 core Xeon chips will complete in essentially the same time as a single SA run running on a single core. In contrast, cutting the number of SA moves to only $1 \times 10^{6}$ as a time-saving measure cannot be recommended for anything other than the simplest of problems - see Table 7. In summary, SDPD calculation times once data have been collected are also not a practical limitation for determining moderately complex crystal structures of pharmaceutical interest.

It is also worth noting the differences in the amounts of sample required, the set-up preparation times and the ease of sample recovery for the three different set-ups. Transmission capillary usually requires $5-10 \mathrm{mg}$ (depending on the width of the capillary) of crystalline material, whereas transmission flat plate and reflection flat plate set-ups require considerably less (ca. $2 \mathrm{mg}$ ). The time taken to pack material into a capillary and align it on the diffractometer can vary between 15 minutes and an hour, depending on the properties of the compound and the width of the capillary - powders that are sticky, are not free-flowing or that carry a static charge can be very difficult to pack. In contrast, with the flat plate instruments it usually takes less than a minute to spread the material out appropriately. Sample recovery is also considerably easier from flat plate setups than from capillaries, although contamination from the vacuum grease used to hold the compound in place in reflection plate setup is a clear concern; on the other hand, since so little compound is used in flat plate setups retrieval may not be a concern. Finally, flat plate setups are more amenable to automated sample changing and thus superior for rapid data collection and sample retrieval.

\section{Conclusions}

Overall, the results suggest that transmission flat plate instruments are a very useful option for SDPD in laboratories that already currently use them only for routine physical form screening and do not 
have easy access to transmission capillary instruments. The quality of the crystal structures obtained from transmission plate instruments can be excellent, while the convenience factor for sample preparation, throughput and retrieval is higher than that of transmission capillary instruments. With such a setup, it is clearly possible to solve crystal structures of similar complexity to the ones shown in this work within an hour of arriving in the laboratory with some polycrystalline material. It is not possible to extrapolate our findings to structures of higher complexity with any degree of confidence, but the molecules presented here are typical of a great many compounds encountered in the pharmaceutical industry, and so the approach is likely to have a wide range of applicability. Whilst we have worked with Bruker diffractometers and the DASH structure solution software, our findings will be applicable to other manufacturers' instruments and other global-optimisation-based structure solution programs. It will be interesting to see if the latest generation of desktop PXRD devices which can operate in transmission and which utilise curved PSDs to collect data over a wide range without scanning, are able to be utilised for SDPD. It can well be imagined that SDPD software such as $D A S H$ can be adapted for routine 'black-box' use on laboratory transmission instruments and that SDPD for practising laboratory chemists could become a rapid turn-around walk-up analytical service, providing ready access to all the insights and understanding that crystal structures bring.

\section{Acknowledgements}

EAK thanks C4X Discovery and the University of Reading, for funding. We are grateful to the University of Reading Chemical Analysis Facility for powder X-ray diffraction instrumentation and to Nick Spencer for technical assistance with this instrumentation.

The diffraction data used in this study are available upon email request to e.kabova@reading.ac.uk. 


\section{Figure captions}

Figure 1. Transmission capillary (black), transmission flat plate (red) and reflection flat plate (blue) powder diffraction data collected from a polycrystalline sample of carvedilol. The effect of preferred orientation on the observed intensities for the reflection flat plate data is clearly evident, particularly in the inset which shows an expanded view of the $16-20^{\circ} 2 \theta$ region of the pattern.

Figure 2. An overlay of the single-crystal structure of carvedilol (green) with the best solution achieved from transmission flat plate data (molecule coloured by atom type). The RMSD of the 15 molecule overlay obtained using the crystal packing similarity feature of Mercury is only $0.118 \AA$. This excellent agreement is evidenced by the virtual superposition of the atoms in the two structures. For clarity, only one of the 15 molecules in the overlay is shown.

Figure 3. An overlay of the single-crystal structure of cefadroxil monohydrate (green) with the best solution achieved from transmission flat plate data (molecule coloured by atom type), viewed down the $b$ axis of the unit cell. The excellent agreement is evidenced by the virtual superposition of the atoms in the two structures. Hydrogen atoms have been omitted for clarity. 


\section{References}

Bushmarinov, I. S., Dmitrienko, A. O., Korlyukov, A. A. \& Antipin, M. Y. (2012). Journal of Applied Crystallography 45, 1187-1197.

Chernyshev, V. V., Kukushkin, S. Y. \& Velikodny, Y. A. (2010). Acta Crystallographica Section EStructure Reports Online 66, 0613-U4977.

Chernyshev, V. V., Machula, A. A., Kukushkin, S. Y. \& Velikodny, Y. A. (2009). Acta Crystallographica Section E-Structure Reports Online 65, 02020-U4391.

David, W. I. F., Shankland, K., van de Streek, J., Pidcock, E., Motherwell, W. D. S. \& Cole, J. C. (2006). Journal of Applied Crystallography 39, 910-915.

Fernandes, P., Shankland, K., Florence, A. J., Shankland, N. \& Johnston, A. (2007). Journal of Pharmaceutical Sciences 96, 1192-1202.

Florence, A. J., Baumgartner, B., Weston, C., Shankland, N., Kennedy, A. R., Shankland, K. \& David, W. I. F. (2003). Journal of Pharmaceutical Sciences 92, 1930-1938.

Griffin, T. A. N., Shankland, K., van de Streek, J. V. \& Cole, J. (2009). Journal of Applied Crystallography 42, 360-361.

Groom, C. R., Bruno, I. J., Lightfoot, M. P. \& Ward, S. C. (2016). Acta Crystallographica Section BStructural Science Crystal Engineering and Materials 72, 171-179.

Groom, C. R. \& Cole, J. C. (2017). Acta Crystallographica Section D-Structural Biology 73, 240-245.

Kabova, E. A., Cole, J. C., Korb, O., Lopez-Ibanez, M., Williams, A. C. \& Shankland, K. (2017). Journal of Applied Crystallography 50, 1411-1420.

Macrae, C. F., Bruno, I. J., Chisholm, J. A., Edgington, P. R., McCabe, P., Pidcock, E., Rodriguez-Monge, L., Taylor, R., van de Streek, J. \& Wood, P. A. (2008). Journal of Applied Crystallography 41, 466-470.

Pawley, G. S. (1981). Journal of Applied Crystallography 14, 357-361.

Shankland, K., David, W. I. F. \& Sivia, D. S. (1997). Journal of Materials Chemistry 7, 569-572.

Shankland, K., Spillman, M. J., Kabova, E. A., Edgeley, D. S. \& Shankland, N. (2013). Acta Crystallographica Section C-Crystal Structure Communications 69, 1251-1259. 
Table 1. Instrumental parameters of the three diffractometers used in this work

\begin{tabular}{llll}
\hline & Instrument 1 & Instrument 2 & Instrument 3 \\
\hline Setup & Transmission capillary & Transmission flat plate & Reflection flat plate \\
System & D8 Advance & D8 Discover & D8 Advance \\
Generator & $40 \mathrm{kV}, 40 \mathrm{~mA}$ & $40 \mathrm{kV}, 40 \mathrm{~mA}$ & $40 \mathrm{kV}, 40 \mathrm{~mA}$ \\
Radiation & $\mathrm{Cu} \mathrm{Ka}{ }_{1}$ & Cu Ka (Göbel mirror) & $\mathrm{Cu} \mathrm{Ka}{ }_{1}$ \\
Geometry & Transmission & Transmission & Reflection \\
Detector & LynxEye & LynxEye & LynxEye \\
Sample holder & Borosilicate glass & Multi-well holder & Zero background \\
& capillary $(\phi=0.7 / 0.5 \mathrm{~mm})$ & (Kapton foil wells) & silicon plate \\
Step size $\left({ }^{\circ} 2 \theta\right)$ & 0.017 & 0.016 & 0.017 \\
\hline
\end{tabular}


Table 2. Compounds used in this work and their key crystallographic parameters

\begin{tabular}{|c|c|c|c|c|c|}
\hline Compound & Structure & DoF & CSD refcode & SpGrp & $\begin{array}{l}\text { Unit cell } \\
\text { parameters }\end{array}$ \\
\hline $\begin{array}{l}\text { Mefenamic } \\
\text { acid }\end{array}$ & & 9 & XYANAC & $P \overline{1}$ & $\begin{array}{l}a=14.556 \AA \\
b=6.811 \AA \\
c=7.657 \AA \\
\alpha=119.57^{\circ} \\
\beta=103.93^{\circ} \\
\gamma=91.30^{\circ}\end{array}$ \\
\hline Indomethacin & & 11 & INDMET01 & $P \overline{1}$ & $\begin{array}{l}a=9.310 \AA \\
b=10.810 \AA \\
c=11.000 \AA \\
\alpha=105.77^{\circ} \\
\beta=93.00^{\circ} \\
\gamma=122.48^{\circ}\end{array}$ \\
\hline Salbutamol & & 11 & BHHPHE & $P b c a$ & $\begin{array}{l}a=21.654 \AA \\
b=8.798 \AA \\
c=14.565 \AA\end{array}$ \\
\hline $\begin{array}{l}\text { Sertraline } \\
\text { hydrochloride }\end{array}$ & & 11 & CAVVUQ & $P 2{ }_{1} 2_{1} 2_{1}$ & $\begin{array}{l}a=7.994 \AA \\
b=8.371 \AA \\
c=25.142 \AA\end{array}$ \\
\hline Sucrose & & 11 & SUCROS01 & $P 2_{1}$ & $\begin{array}{l}a=7.724 \AA \\
b=8.679 \AA \\
c=10.824 \AA \\
\beta=10.2 .98^{\circ}\end{array}$ \\
\hline $\begin{array}{l}\text { Cefadroxil } \\
\text { hydrate }\end{array}$ & & 14 & JOSWAP & $P 2{ }_{1} 2_{1} 2_{1}$ & $\begin{array}{l}\mathrm{a}=11.038 \AA \\
\mathrm{b}=11.211 \AA \\
\mathrm{c}=14.436 \AA\end{array}$ \\
\hline Carvedilol & & 16 & GIVJUQ01 & $P 2_{1} / C$ & $\begin{array}{l}a=15.541 \AA \\
b=15.205 \AA \\
c=9.117 \AA \\
\beta=100.37^{\circ}\end{array}$ \\
\hline Furosemide & & 22 & FURSEM01 & $P \overline{1}$ & $\begin{array}{l}a=10.467 \AA \\
b=15.801 \AA \\
c=9.584 \AA \\
\alpha=71.87^{\circ} \\
\beta=115.04^{\circ} \\
\gamma=108.48^{\circ}\end{array}$ \\
\hline
\end{tabular}


Table 3. PXRD data collection parameters

\begin{tabular}{llllll}
\hline & Range $/{ }^{\circ} 2 \theta$ & \multicolumn{3}{c}{ Scan speed $/ \mathrm{s} \mathrm{step}^{-1}$} & Collection time / hrs \\
& & $\begin{array}{l}\text { Transmission } \\
\text { capillary }\end{array}$ & $\begin{array}{l}\text { Transmission } \\
\text { flat plate }\end{array}$ & $\begin{array}{l}\text { Reflection } \\
\text { flat plate }\end{array}$ & \\
\hline Mefenamic acid & $4-45$ & 1.4 & 1.5 & 1.4 & ca.1 \\
Indomethacin & $4-45$ & 1.4 & 1.5 & 1.4 & ca.1 \\
Salbutamol & $4-45$ & 1.4 & 1.5 & 1.4 & ca.1 \\
Sertraline $\mathrm{HCl}$ & $4-45$ & 1.4 & 1.5 & 1.4 & ca.1 \\
Sucrose & $4-45$ & 1.4 & 1.5 & 1.4 & ca.1 \\
Cefadroxil $\mathrm{H}_{2} \mathrm{O}$ & $4-45$ & 1.4 & 1.5 & 1.4 & ca.1 \\
Carvedilol & $4-55$ & 4.3 & 4.3 & 4.3 & ca.4 \\
Furosemide & $4-45$ & 1.4 & 1.5 & 1.4 & ca.1 \\
\hline
\end{tabular}


Table 4. Upper $2 \theta$ limits and equivalent maximum resolutions for the various Pawley fits performed in this work

\begin{tabular}{|c|c|c|c|c|c|c|}
\hline & \multicolumn{2}{|c|}{ Transmission capillary } & \multicolumn{2}{|c|}{ Transmission flat plate } & \multicolumn{2}{|c|}{ Reflection flat plate } \\
\hline & $\operatorname{Max} .2 \theta / \circ$ & Res. / A & $\operatorname{Max} .2 \theta / \circ$ & Res. / Å & $\operatorname{Max} .2 \theta / \circ$ & Res. / Å \\
\hline Mefenamic acid & 45.0 & 2.01 & 40.0 & 2.25 & 45.0 & 2.01 \\
\hline Indomethacin & 45.0 & 2.01 & 42.0 & 2.15 & 45.0 & 2.01 \\
\hline Salbutamol & 45.0 & 2.01 & 45.0 & 2.01 & 45.0 & 2.01 \\
\hline Sertraline $\mathrm{HCl}$ & 45.0 & 2.01 & 42.8 & 2.11 & 45.0 & 2.01 \\
\hline Sucrose & 45.0 & 2.01 & 45.0 & 2.01 & 45.0 & 2.01 \\
\hline Cefadroxil $\mathrm{H}_{2} \mathrm{O}$ & 45.0 & 2.01 & 45.0 & 2.01 & 45.0 & 2.01 \\
\hline Carvedilol & 52.2 & 1.75 & 42.6 & 2.12 & 45.0 & 2.01 \\
\hline Furosemide & 40.0 & 2.25 & 32.8 & 2.73 & 40.0 & 2.25 \\
\hline
\end{tabular}


Table 5. Full width at half maximum values obtained using $D A S H$ (Voigt function with correction for axial divergence) for selected peaks in carvedilol

\begin{tabular}{llll}
\hline Peak position $/{ }^{\circ} 2 \theta$ & $\begin{array}{c}\text { Full width at half maximum } /{ }^{\circ} \\
\text { Transmission } \\
\text { capillary }\end{array}$ & $\begin{array}{l}\text { Transmission flat } \\
\text { plate }\end{array}$ & $\begin{array}{l}\text { Reflection flat } \\
\text { plate }\end{array}$ \\
\hline 5.843 & 0.067 & 0.098 & 0.089 \\
11.428 & 0.069 & 0.097 & 0.074 \\
11.919 & 0.077 & 0.096 & 0.086 \\
13.700 & 0.067 & 0.101 & 0.085 \\
15.252 & 0.067 & 0.100 & 0.070 \\
15.620 & 0.068 & 0.101 & 0.072 \\
\hline
\end{tabular}


Table 6. Success rate (\%) in determining crystal structures from 50 SA runs each comprising $5 \times 10^{6}$ $S A$ moves. For the reflection flat plate setup, results are shown not only for no preferred orientation correction included in $D A S H$ but also for three distinct preferred orientation corrections in $D A S H$, indicated (hkl)

\begin{tabular}{lllrrrr}
\hline & $\begin{array}{l}\text { Transmission } \\
\text { capillary }\end{array}$ & $\begin{array}{l}\text { Transmission flat } \\
\text { plate }\end{array}$ & No PO & $(100)$ & $(010)$ & $(001)$ \\
& & & 98 & 76 & 90 & 76 \\
\hline Mefenamic acid & 98 & 98 & 2 & 30 & 2 & 42 \\
Indomethacin & 100 & 50 & 0 & 0 & 0 & 0 \\
Salbutamol & 100 & 100 & 0 & 0 & 0 & 0 \\
Sertraline $\mathrm{HCl}$ & 100 & 100 & 48 & 22 & 50 & 32 \\
Sucrose & 100 & 100 & 18 & 8 & 4 & 4 \\
Cefadroxil $\mathrm{H}_{2} \mathrm{O}$ & 58 & 22 & 0 & 0 & 0 & $10\left(^{*}\right)$ \\
Carvedilol 4hrs & 22 & 32 & 0 & 0 & 0 & 0 \\
Furosemide & $34\left(^{*}\right)$ & $34\left(^{*}\right)$ & & &
\end{tabular}


Table 7. Root mean square deviations $(\AA)$ of solved crystal structures (obtained using $5 \times 10^{6} \mathrm{SA}$ moves) from known single crystal structures, obtained using the crystal packing similarity feature of Mercury

\begin{tabular}{llll}
\hline & Transmission capillary & Transmission flat plate & Reflection flat plate \\
\hline Mefenamic acid & 0.052 & 0.079 & 0.228 \\
Indomethacin & 0.158 & 0.248 & 0.212 \\
Salbutamol & 0.072 & 0.097 & \\
Sertraline $\mathrm{HCl}$ & 0.036 & 0.068 & \\
Sucrose & 0.038 & 0.071 & 0.095 \\
Cefadroxil $\mathrm{H}_{2} \mathrm{O}$ & 0.055 & 0.100 & 0.208 \\
Carvedilol 4hrs & 0.115 & 0.118 & $0.452^{*}$ \\
Furosemide & $0.888\left(0.132^{* *}\right)$ & 0.987 & \\
\hline
\end{tabular}

${ }^{*}$ solution achieved with the use of PO correction in the (001) direction

${ }^{* *}$ solution achieved with the use of PO correction in the (010) direction 
Table 8. Success rate (\%) in determining crystal structures from 50 SA runs each comprising $1 \times 10^{6}$ SA moves. For the reflection flat plate setup, results are shown for not only for no preferred orientation correction included in $D A S H$ but also for three distinct preferred orientation corrections in $D A S H$, indicated $(\mathrm{hkl})$

\begin{tabular}{lllrrrr}
\hline & $\begin{array}{l}\text { Transmission } \\
\text { capillary }\end{array}$ & $\begin{array}{l}\text { Transmission } \\
\text { flat plate }\end{array}$ & No PO & $(100)$ & $(010)$ & $(001)$ \\
\hline Mefenamic acid & 96 & 94 & 42 & 54 & 48 & 44 \\
Indomethacin & 68 & 22 & 2 & 2 & 0 & 0 \\
Salbutamol & 80 & 46 & 0 & 0 & 0 & 0 \\
Sertraline HCl & 38 & 40 & 0 & 0 & 0 & 0 \\
Sucrose & 96 & 78 & 0 & 0 & 0 & 4 \\
Cefadroxil $\mathrm{H}_{2} \mathrm{O}$ & 2 & 0 & 0 & 0 & 0 & 0 \\
Carvedilol 4hrs & 0 & $2\left(^{*}\right)$ & 0 & 0 & 0 & 0 \\
Furosemide & 0 & 0 & 0 & 0 & 0 & 0 \\
\hline
\end{tabular}

$\left(^{*}\right)$ some additional Rietveld refinement required - see discussion 


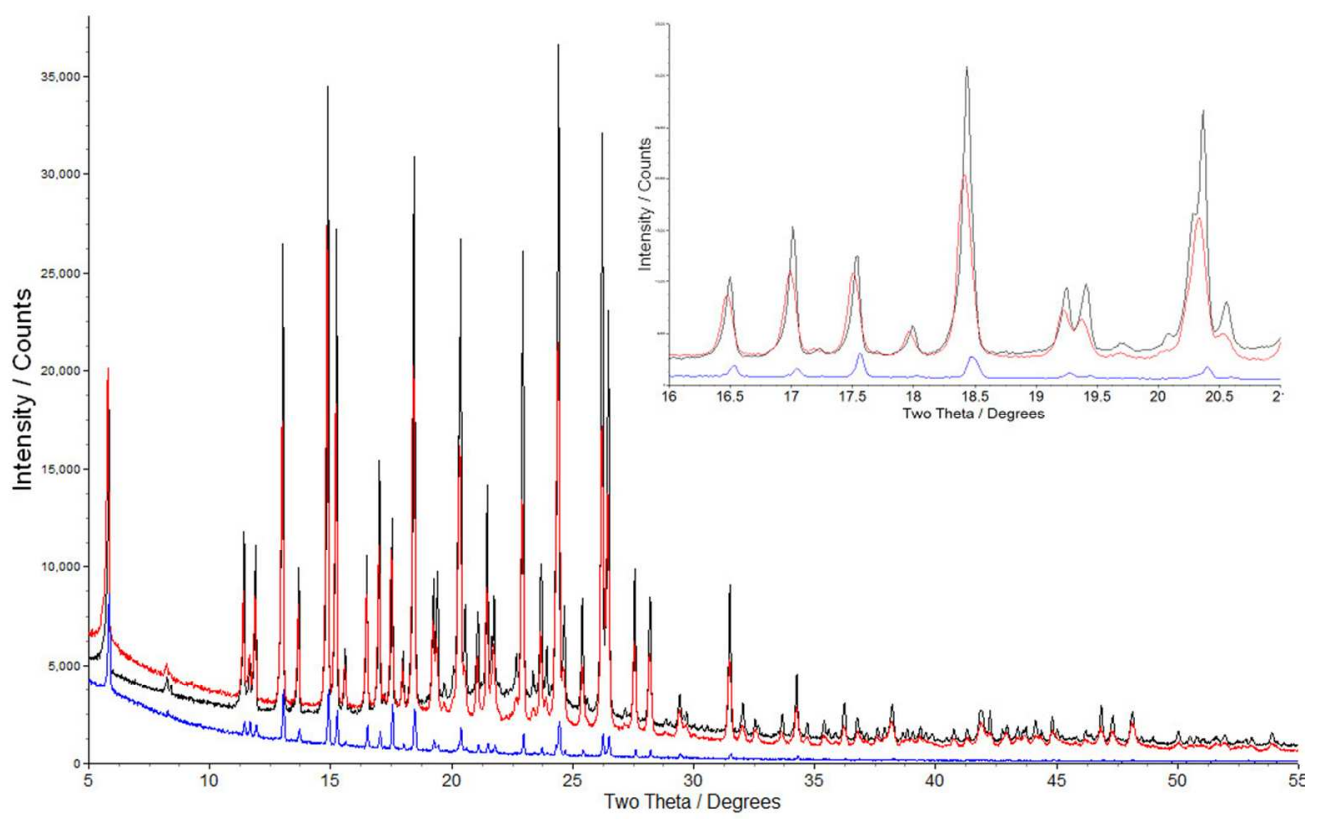

Transmission capillary (black), transmission flat plate (red) and reflection flat plate (blue) powder diffraction data collected from a polycrystalline sample of carvedilol. The effect of preferred orientation on the observed intensities for the reflection flat plate data is clearly evident, particularly in the inset which shows an expanded view of the $16-20^{\circ} 2 \Theta$ region of the pattern.

$376 \times 233 \mathrm{~mm}(72 \times 72 \mathrm{DPI})$ 


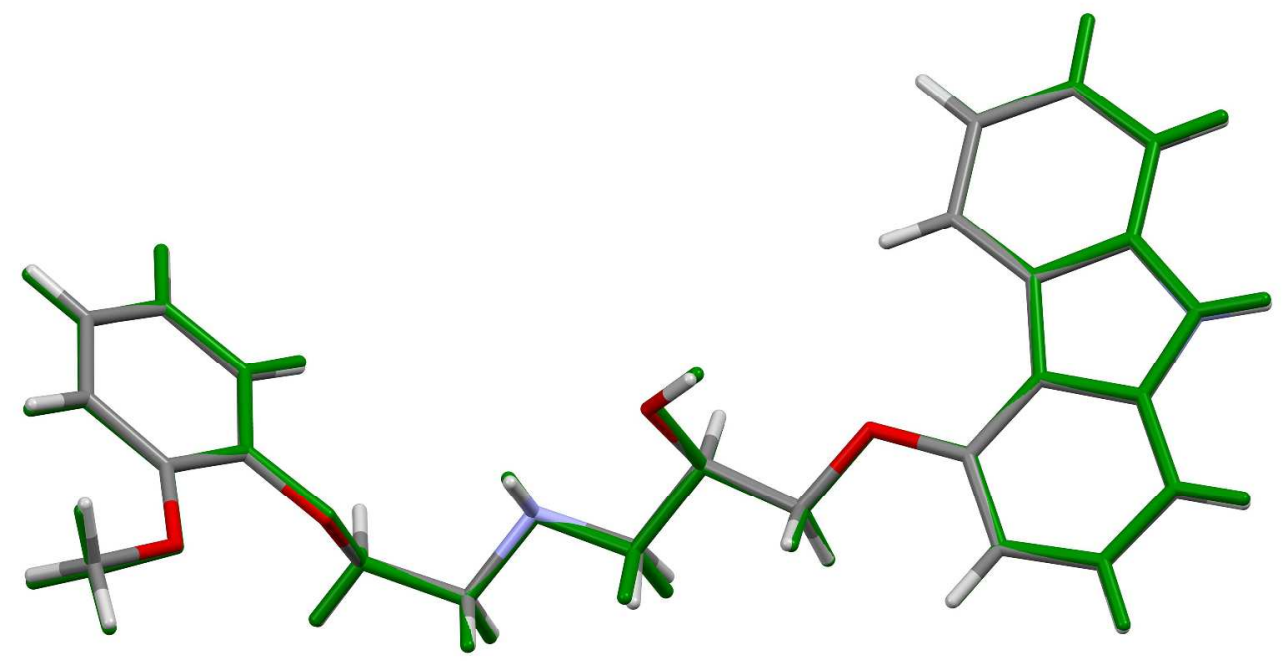

An overlay of the single-crystal structure of carvedilol (green) with the best solution achieved from transmission flat plate data (molecule coloured by atom type). The RMSD of the 15 molecule overlay obtained using the crystal packing similarity feature of Mercury is only $0.118 \AA$. This excellent agreement is evidenced by the virtual superposition of the atoms in the two structures. For clarity, only one of the 15 molecules in the overlay is shown.

$1112 \times 682 \mathrm{~mm}(96 \times 96 \mathrm{DPI})$ 


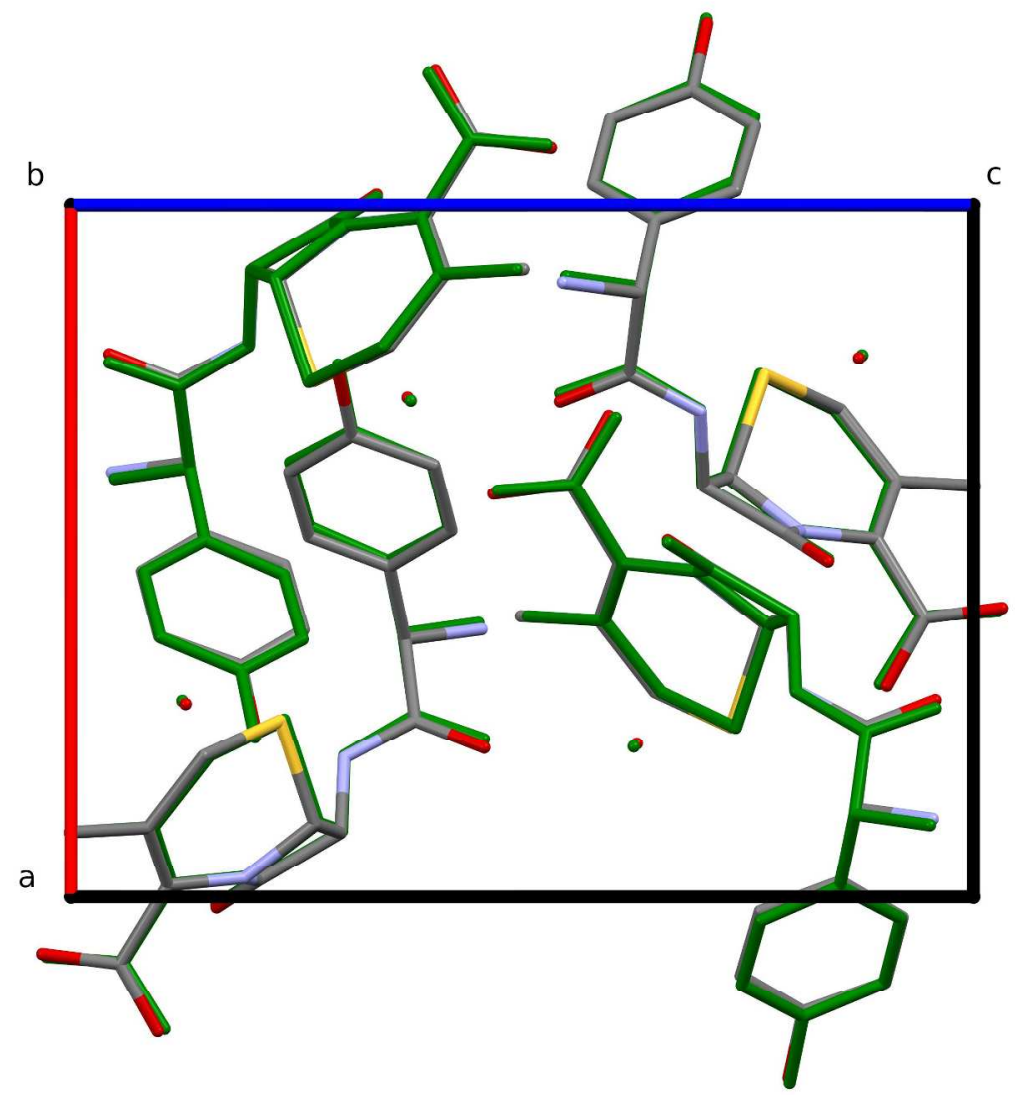

An overlay of the single-crystal structure of cefadroxil monohydrate (green) with the best solution achieved from transmission flat plate data (molecule coloured by atom type), viewed down the $b$ axis of the unit cell. The excellent agreement is evidenced by the virtual superposition of the atoms in the two structures. Hydrogen atoms have been omitted for clarity.

$814 \times 703 \mathrm{~mm}(96 \times 96 \mathrm{DPI})$ 


\section{SUPPORTING INFORMATION}

Pushing the limits of molecular crystal structure determination from powder diffraction data in high-throughput chemical environments

Elena A. Kabova ${ }^{1, *}$, Charles D. Blundell ${ }^{2}$ and Kenneth Shankland ${ }^{1}$

${ }^{1}$ School of Pharmacy, University of Reading, Whiteknights, P.O. Box 224, Reading, RG6 6AD, United Kingdom

${ }^{2}$ C4X Discovery, Manchester One, 53 Portland Street, Manchester, M1 3LD, United Kingdom

* Correspondence to: Elena Kabova (Telephone: +44 118378 7425). E-mail address: e.kabova@reading.ac.uk. 
Fig. S1. PXRD data for mefenamic acid. Capillary (black), transmission flat plate (red), reflection flat plate (blue).

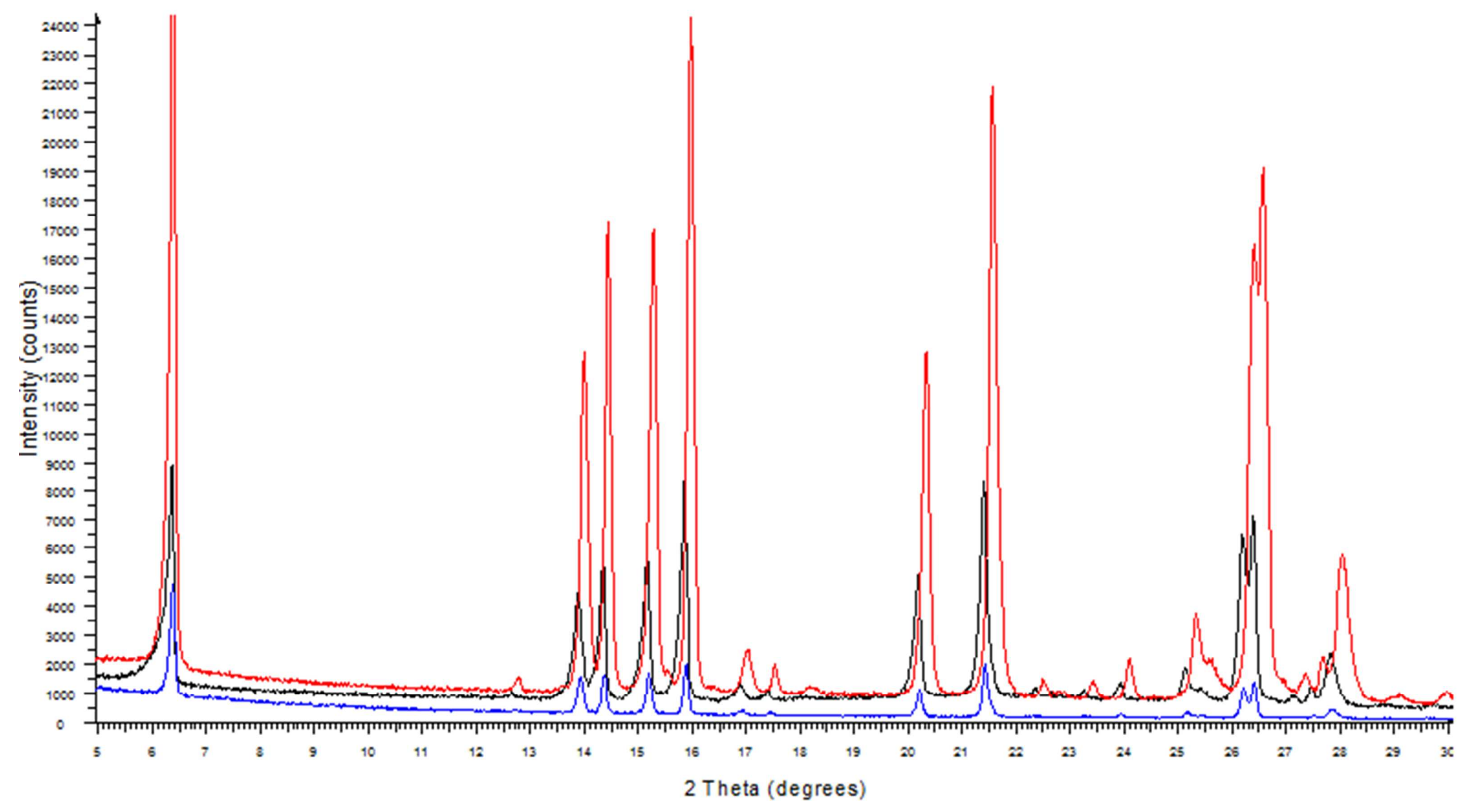


Fig. S2. PXRD data for indomethacin. Capillary (black), transmission flat plate (red), reflection flat plate (blue).

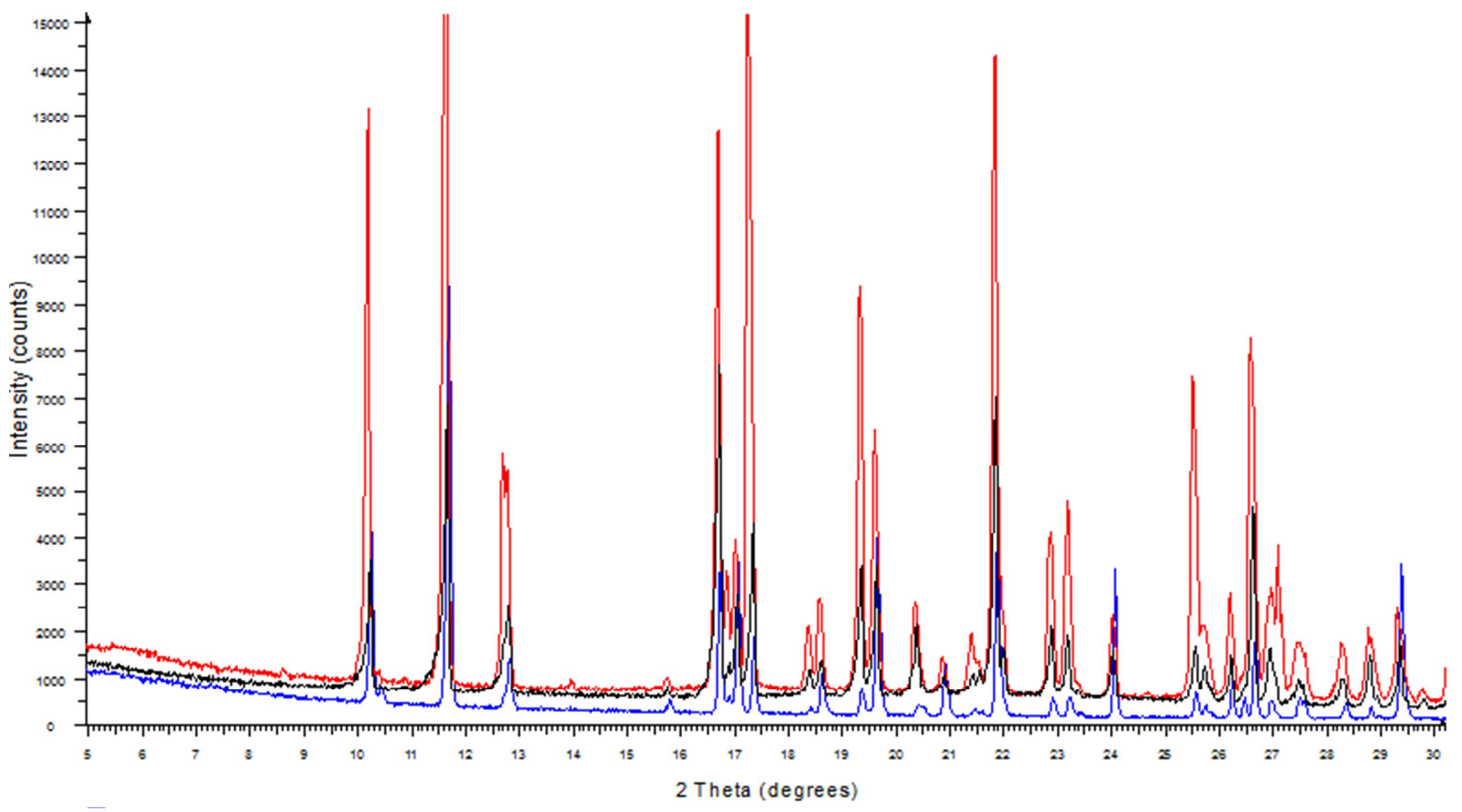


Fig. S3. PXRD data for salbutamol. Capillary (black), transmission flat plate (red), reflection flat plate (blue).

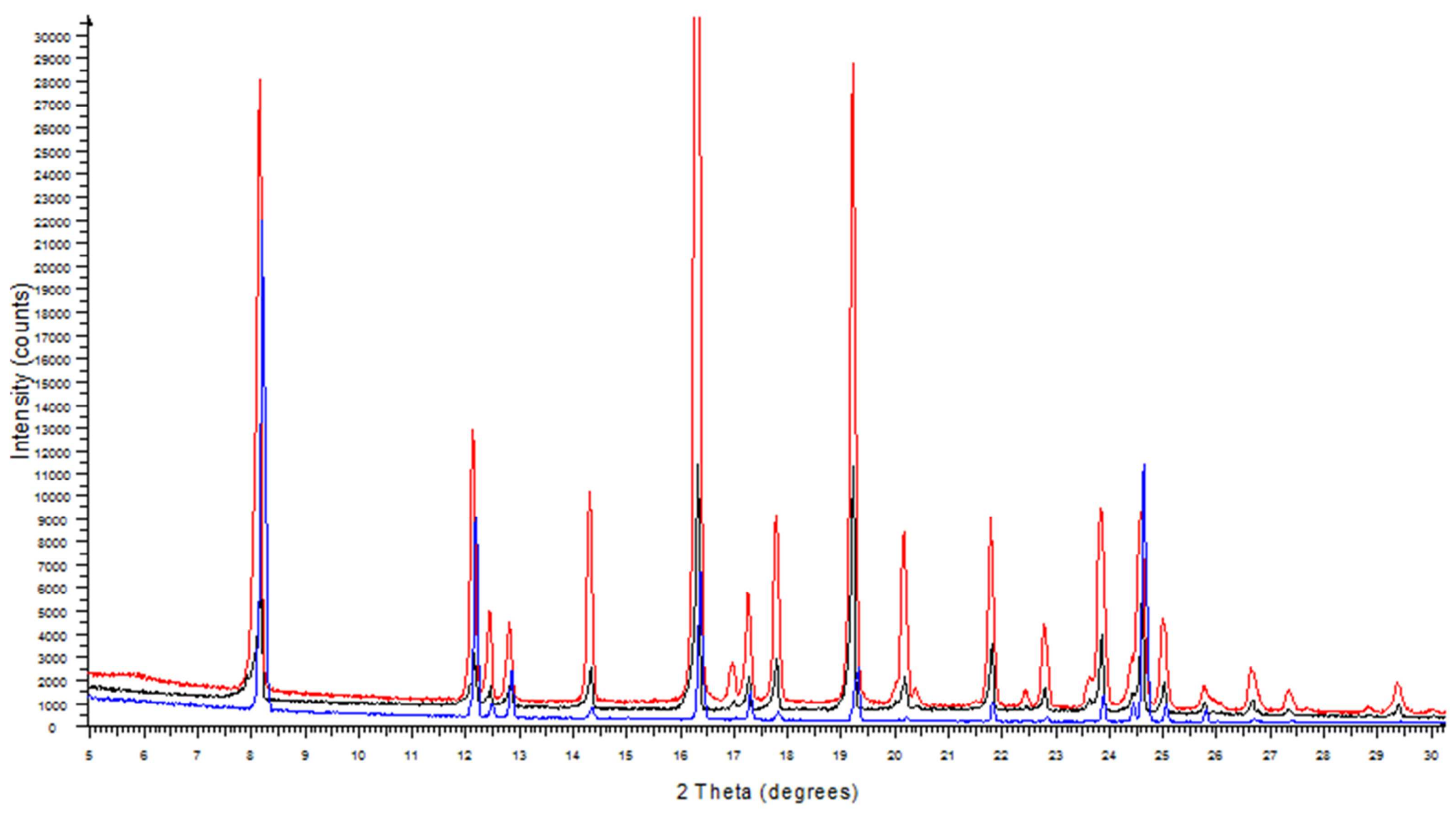


Fig. S4. PXRD data for sertraline. Capillary (black), transmission flat plate (red), reflection flat plate (blue).

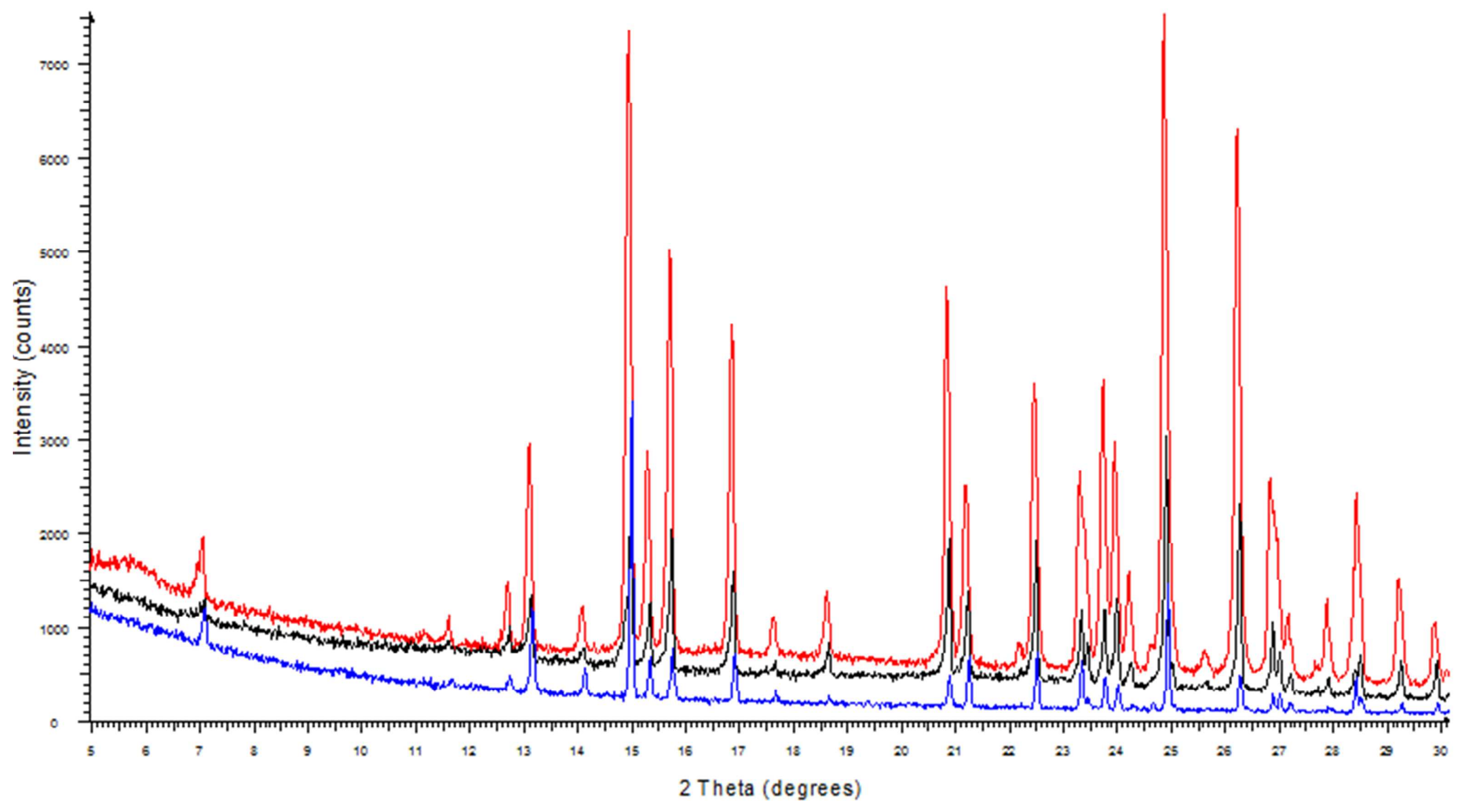


Fig. S5. PXRD data for sucrose. Capillary (black), transmission flat plate (red), reflection flat plate (blue).

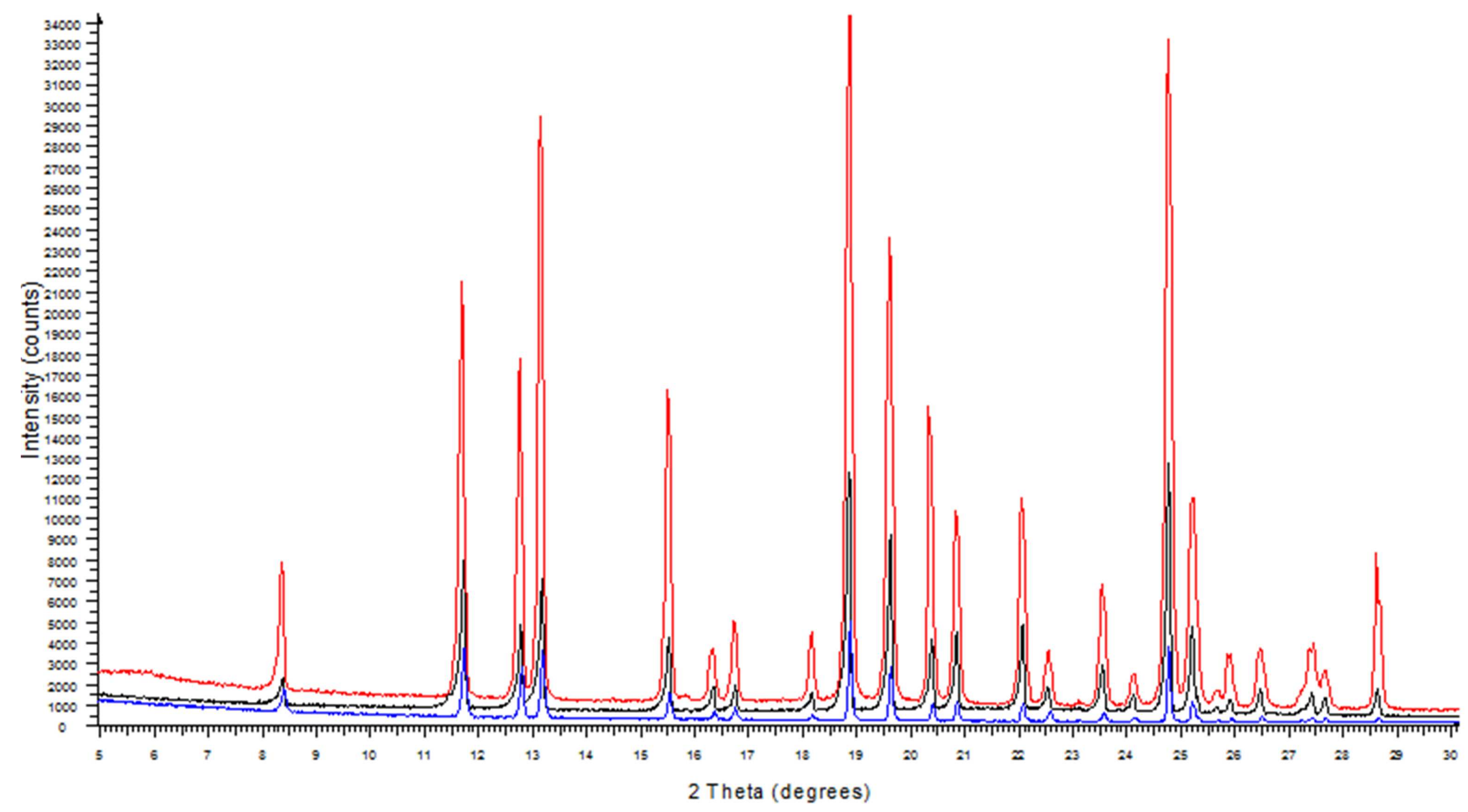


Fig. S6. PXRD data for cefadroxil monohydrate. Capillary (black), transmission flat plate (red), reflection flat plate (blue).

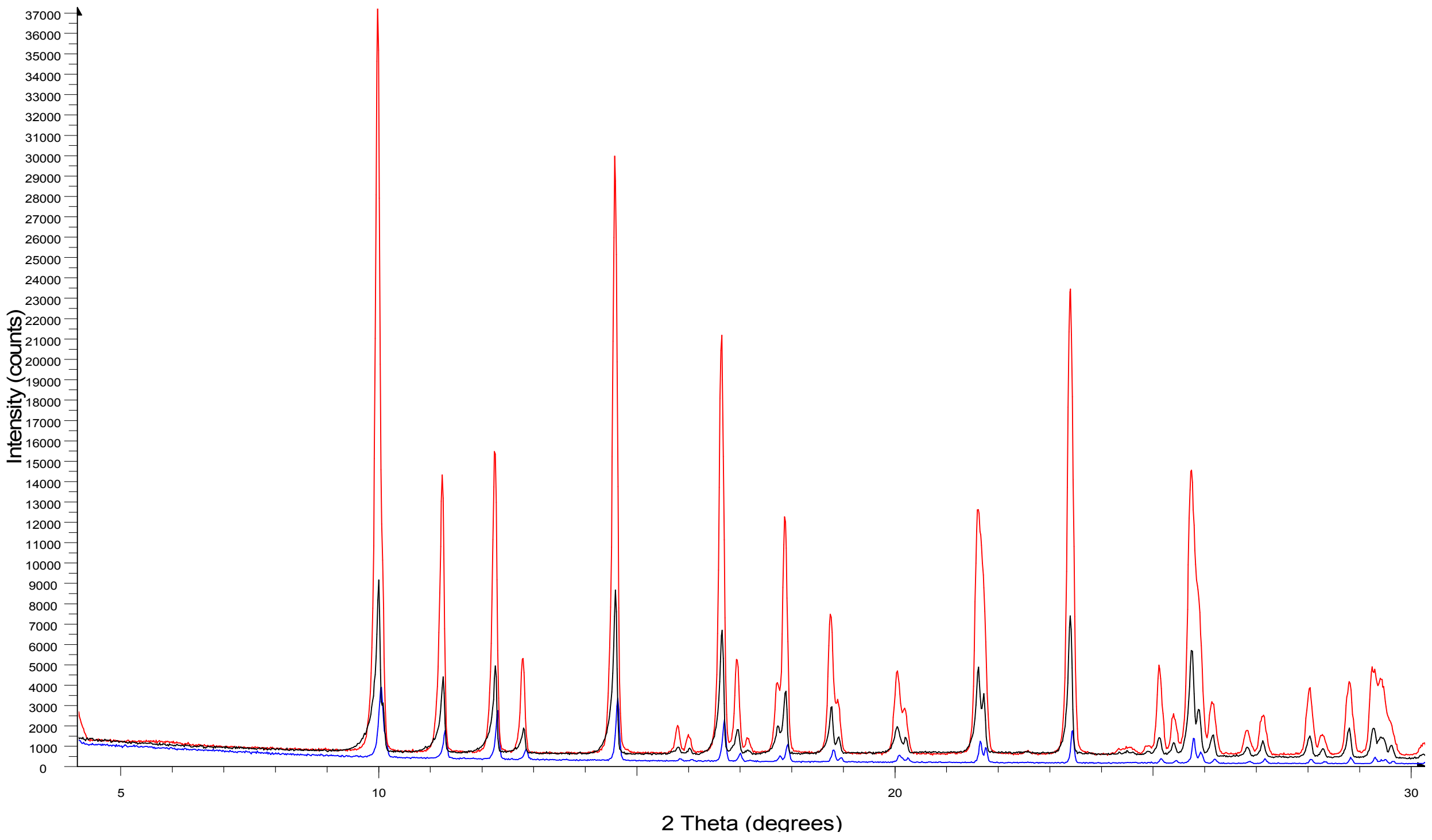


Fig. S7. PXRD data for carvedilol. Capillary (black), transmission flat plate (red), reflection flat plate (blue).

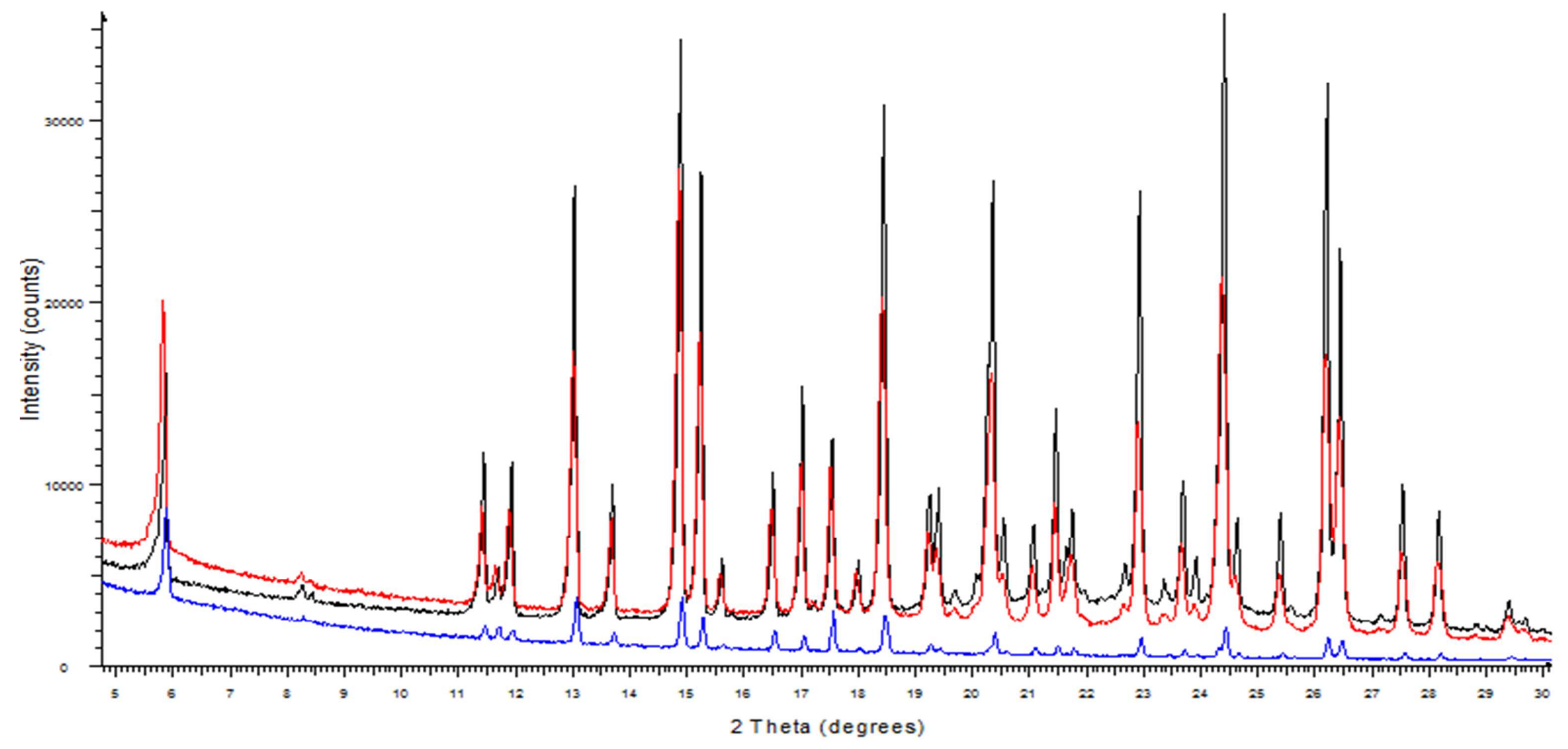


Fig. S8. PXRD data for furosemide. Capillary (black), transmission flat plate (red), reflection flat plate (blue).

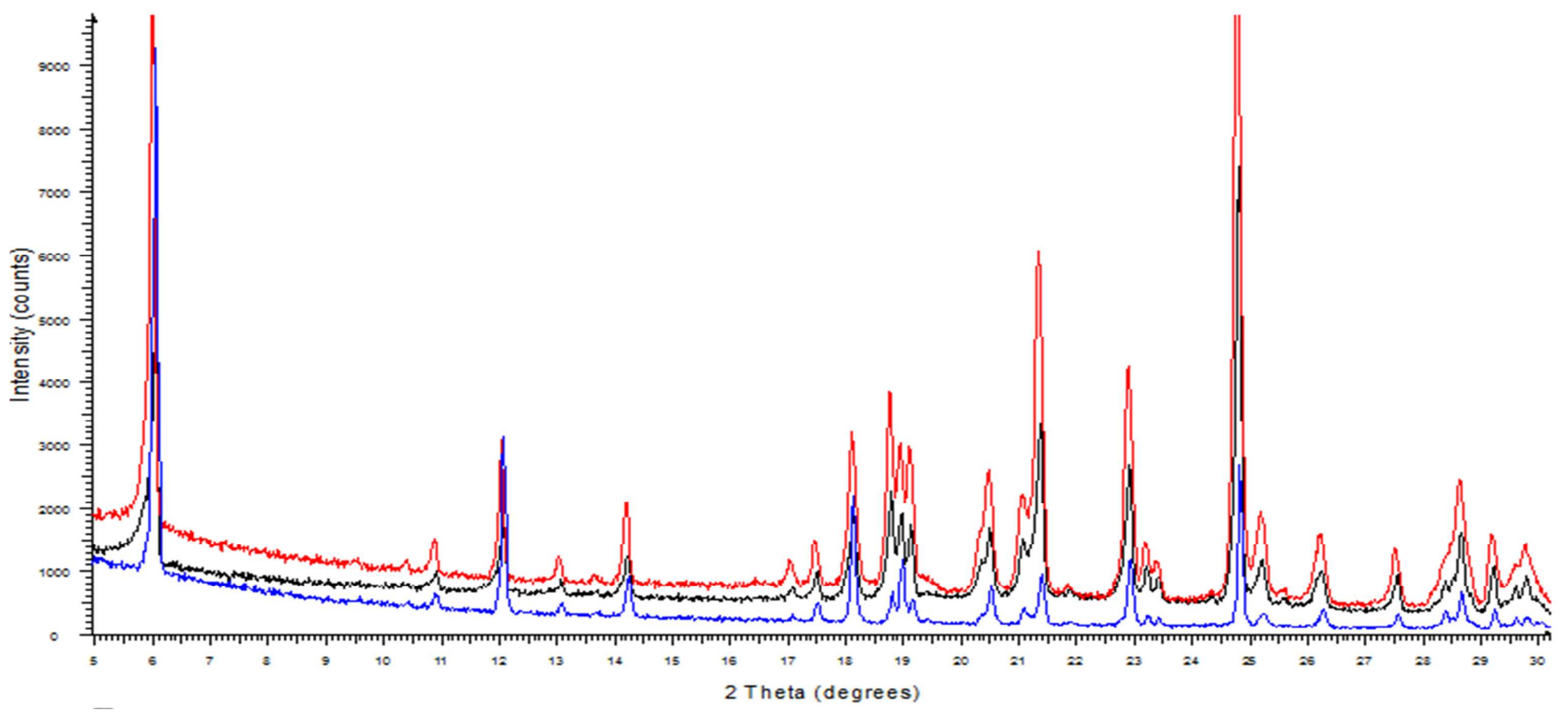


Fig. S9. The overlays of the single-crystal structures (in green) and the corresponding best capillary DASH solutions (molecules coloured by atom type) for a) mefenamic acid, b) indomethacin, c) salbutamol, d) sertraline hydrochloride, e) sucrose, f) cefadroxil hydrate g) carvedilol and h) furosemide. For clarity, only one of the 15 molecules in the overlays is shown.

a)

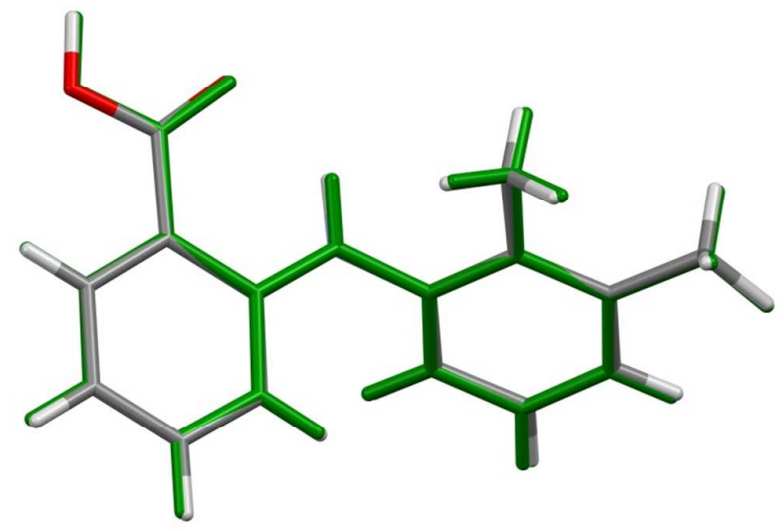

b)
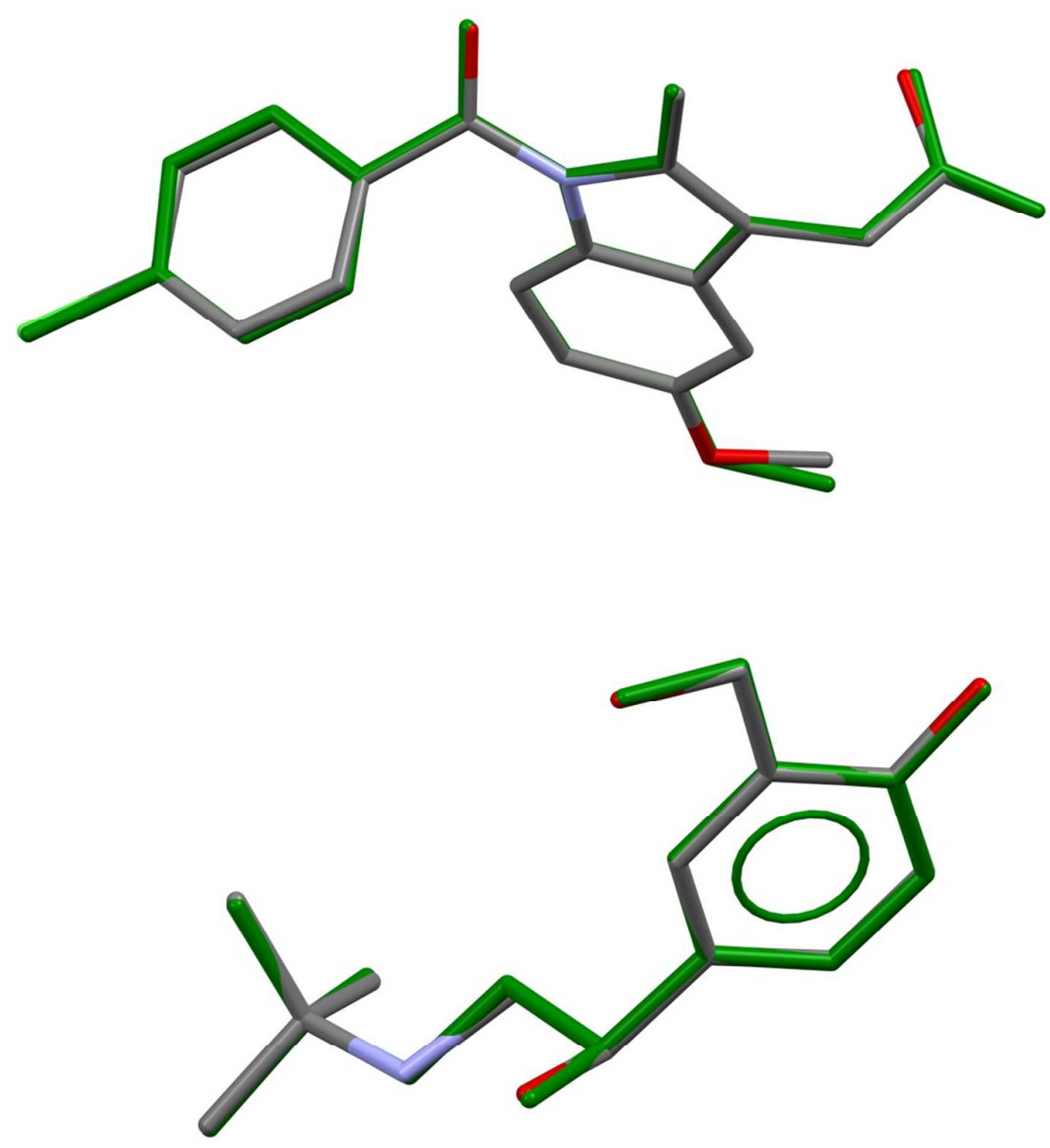

c) 
Fig. S9. Continued.

d)

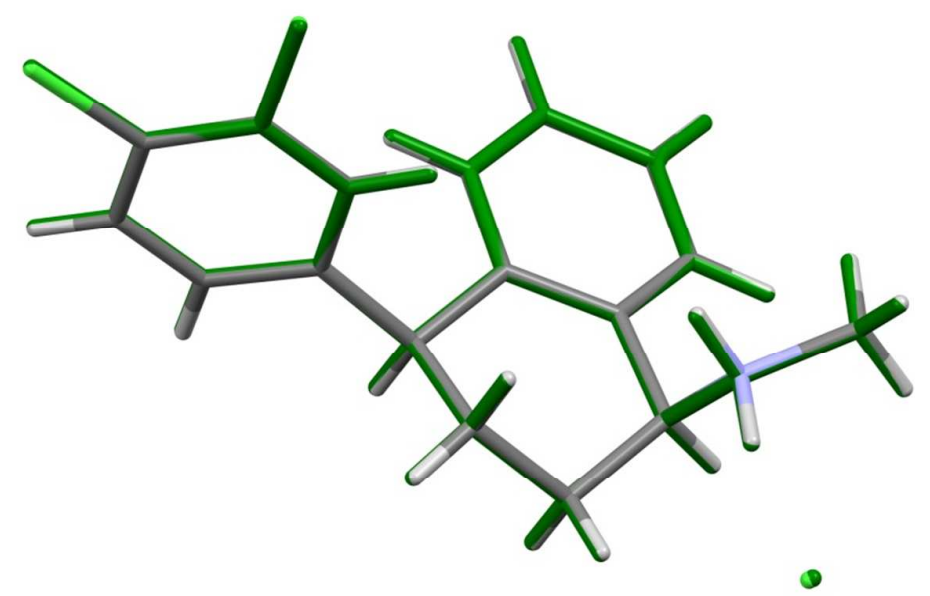

e)
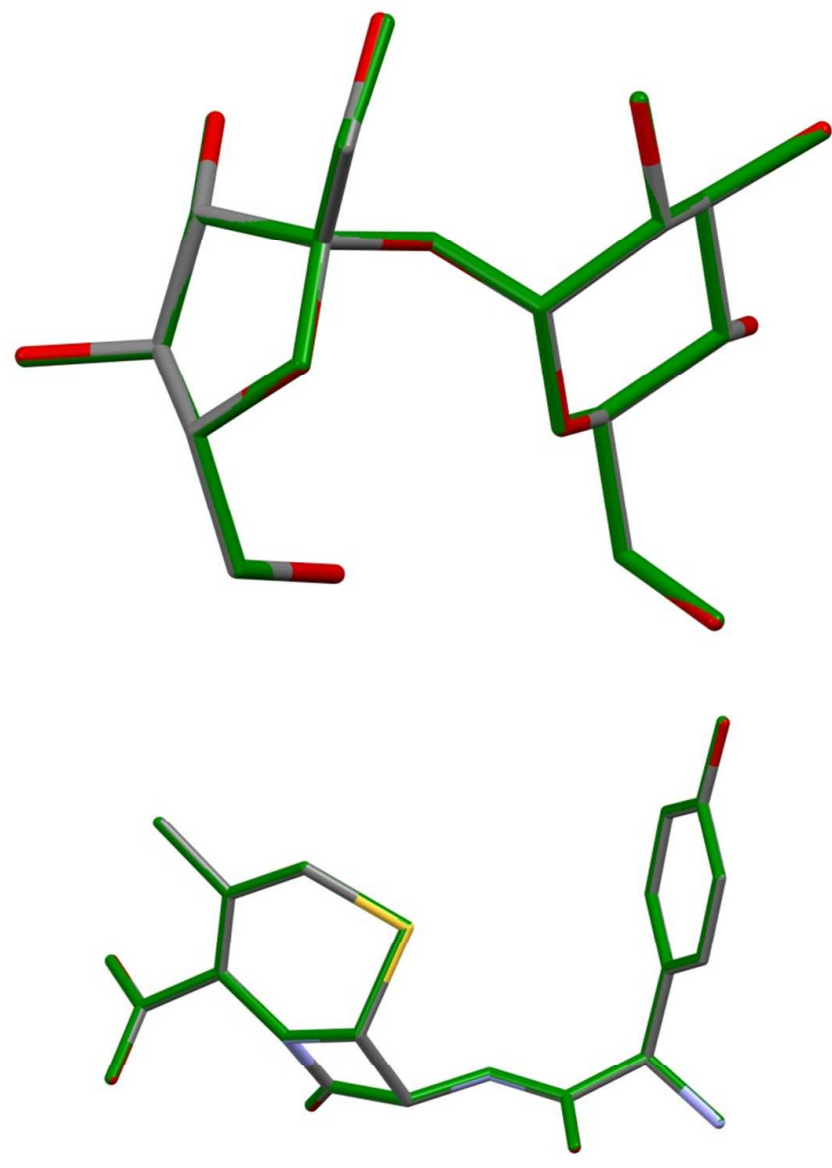

f) 
Fig. S9. Continued

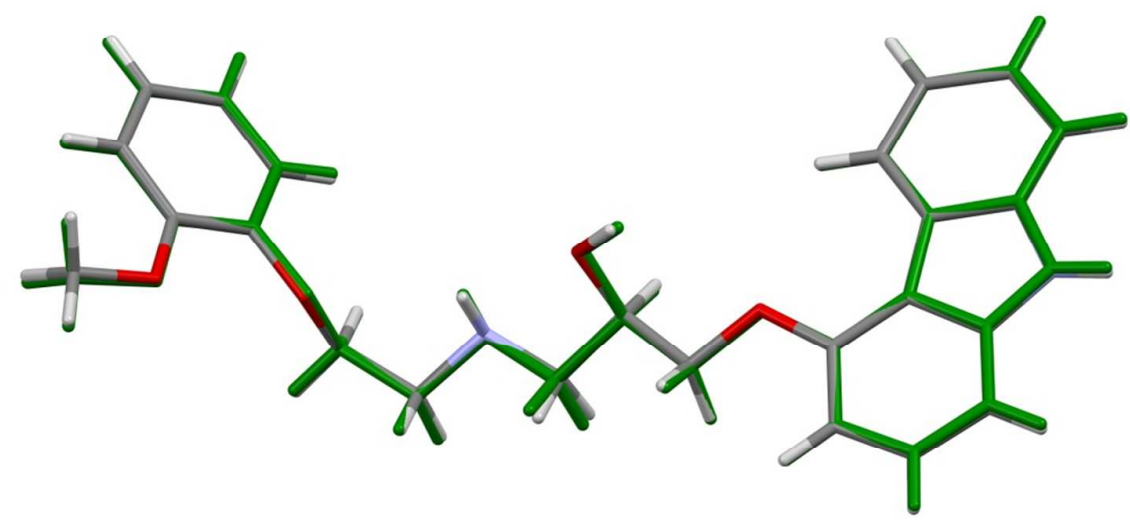

g)

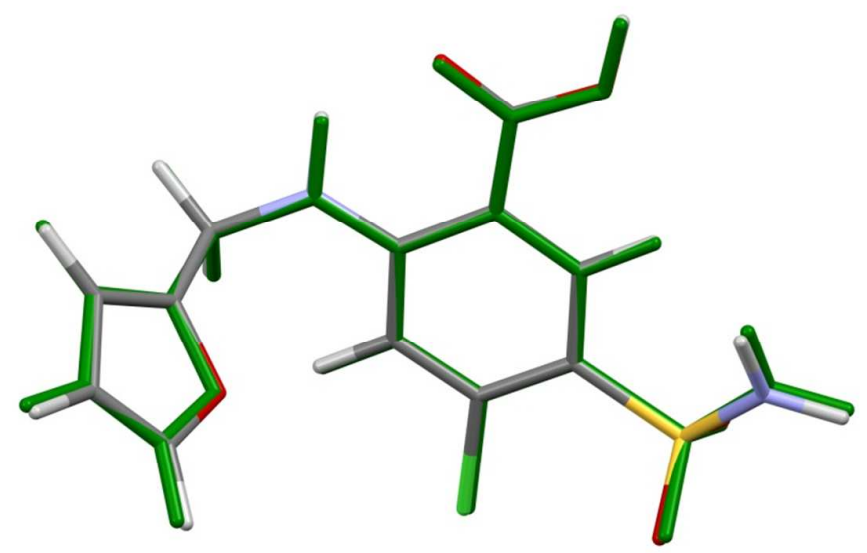

h) 